\title{
STATISTICAL MODELING FOR LASER INDUCED DAMAGE THRESHOLD
}

\author{
Leonidas Sakalauskas ${ }^{1}$, Ingrida Vaiciulyte ${ }^{2}$ \\ ${ }^{1}$ Klaipeda University, Klaipeda, Lithuania, e-mail: leonidas.sakalauskas@mif.vu.lt; \\ ${ }^{2}$ Šiauliai State College, Šiauliai, Lithuania, e-mail: i.vaiciulyte@svako.lt
}

Abstract. Monte Carlo experiments are an efficient tool for investigation of the LaserInduced Damage Threshold (LIDT) testing with pulsed lasers. In this study, the approach of sequential Monte Carlo search is developed for LIDT testing with bundle of laser pulses and compared with the approach of Sample Average Approximation (SAA). The likelihood ratio test is applied to accept or reject the hypothesis about the data distribution.

Key words: Laser Induced Damage Threshold, Monte Carlo method, Sample Average Approximation, Maximum Likelihood.

\section{Introduction}

Laser-induced damage is based on the interaction of the laser intensity and the tested material. The laser radiation bundle is characterized by a high energy density. Due to this property the material is heating with lasers to very high thermal, that result the different structures are formed on the material. The laser treatment provides to treat composite surface and reduces the extent of damage to the treated surfaces. On this reason, the research in laser science is so active. Laser-induced damage intention to raise Laser-Induced Damage Threshold (LITD) to irradiating samples. In this paper, Monte Carlo method for LIDT testing with bundle of laser pulses is developed. Computer simulation representing the statistical modeling by maximum likelihood estimation is applied.

\section{Likelihood Function of LIDT}

Assume the optical material be tested by series of laser pulses. Each pulse is affecting the material and their bundle can achieve the damage threshold more than separated pulses. Let us consider for simplicity the bundle from $I \geq 1$ pulses. Assume distribution of pulse fluencies be normal with parameters of expected peak fluence $F$ and standard deviation $\sigma_{F}=s \cdot \sqrt{F}$. Thus the bundle of pulses $\vec{F}=\left(F_{1}, F_{2}, \ldots, F_{I}\right)$ consists of pulses, where fluence of the $i^{\text {th }}$ pulse is $F_{i}=F+\eta_{i} \cdot \sigma_{F}$, where $\eta_{i}$ is standard normal. According to Batavičiute et al. (2013), Porteus and Seitel (1984), Bernhardt and Starke (1994) the probability of damage is as follows:

$$
P(\vec{F}, \gamma)=1-\exp \left(-M \cdot S \cdot \sum_{\sum_{j=1}^{i} \gamma^{i-j} \cdot F_{j}>T} \ln \left(\frac{\sum_{j=1}^{i} \gamma^{i-j} \cdot F_{j}}{T}\right)\right),
$$


where $M$ is average defect density, $S$ - surface, $T$ - threshold, $\gamma$ is the variable which evaluates the remaining deformation during time interval between adjacent pulses, $T$ also can be considered as normal with standard deviation $s t$.

Density of laser pulse energy fluctuations (Batavičiute et al., 2013):

$$
\operatorname{PDF}_{F}\left(\vec{F}, \sigma_{F}\right)=\frac{e^{-\sum_{i=1}^{I}\left(F_{i}-F\right)^{2}}}{(2 \cdot \pi)^{\frac{i}{2}} \cdot \sigma_{F}{ }^{i}},
$$

where $\sigma_{F}$ is standard deviation of fluctuations, and pulses are assumed irradiated independently.

The convolution of probability of number of $k$ damaged outcomes from $n$ trials after some manipulation is as follows (Batavičiute et al., 2013):

$$
P D F(T, M, \gamma \mid k, n, \vec{F})=\int_{\Re^{l}}\left(\begin{array}{l}
n \\
k
\end{array}\right) \cdot P(\vec{F}, \gamma)^{k} \cdot(1-P(\vec{F}, \gamma))^{n-k} \cdot P D F_{F}\left(\vec{F}, \sigma_{F}\right) \cdot d \vec{F}
$$

where $F_{i}$ are measured pulse fluencies, $F$ - averaged applied fluence.

Note that standard deviation of pulse intensity fluctuation is increasing as averaged applied fluence intensity increased. Therefore it is reasonable for modeling of standard deviation apply Taylor's law (Taylor, 1961):

$$
\sigma_{F}=s \cdot F^{\theta}
$$

where usually $\theta=0.5$.

Since convolution of probability of number of damages is a multivariate integral, the Sample Average Approximation (SAA) of Monte Carlo method is developed. According to SAA the random sample is simulated and remains fixed for analysis and estimation (Shapiro et al., 2009). This approach can be compared with search when the series of Monte Carlo samples is generated with adaptively changed sample size (Sakalauskas, 2002).

Thus the Monte Carlo estimation of the log-likelihood function is as follows:

$$
L(T, M, \gamma)=-\sum_{i=1}^{K} \ln \left(\frac{1}{N} \sum_{i=1}^{N}\left(\begin{array}{l}
n \\
k_{i}
\end{array}\right) \cdot P\left(\vec{F}_{i, i i}, \gamma\right)^{k_{i}} \cdot\left(1-P\left(\vec{F}_{i, i}, \gamma\right)\right)^{n-k_{i}}\right),
$$

where samples $\vec{F}$ are normally distributed.

\section{Computer Simulation.}

Assume $M=1000$ defects $/ \mathrm{cm}^{2}, S=\pi \cdot R^{2}$, where $R=500 \mu \mathrm{m}, \gamma=0.5, s=5 \%$, $\theta=0.5, n_{i} \equiv n=50$, threshold $T=37 \mathrm{~J} / \mathrm{cm}^{2}, F_{i}=F_{a p}+i \cdot \Delta F, 1 \leq i \leq 50$. 
Sequence of successful outcomes $k_{i}$ has been simulated randomly by MathCad subroutine $\operatorname{rbinom}\left(k_{i}, n, P(\vec{F})\right), 1 \leq i \leq 50$. The random sample of fluencies of pulses was generated as well of size $N=100$.

Note that only small interval $F_{a p}, F_{a p}+50 \cdot \Delta F$ of fluence exists in which some damage dynamic occurs, because the left of this interval probability of damage is zero and on the right - the probability of damage is one.

Table 1. Chosen intervals of fluence

\begin{tabular}{r|ll} 
& $F_{a p}$ & $\Delta F$ \\
$I=1$ & 0 & 1 \\
$I=10$ & 18.2 & 0.05 \\
$I=100$ & 18.2 & 0.01 \\
$I=1000$ & 18.15 & 0.005
\end{tabular}

The $\log$-likelihood function at the initial data $L(T, M, \gamma)$ and after minimization the decreased function $L\left(T_{\min }, M_{\min }, \gamma_{\min }\right)$, with optimal value shown in Table 2.

Table 2. Optimal values

\begin{tabular}{|c|c|c|c|c|c|c|}
\hline & $L(T, M$ & $L\left(T_{\min }, M_{\text {min }}, \hat{\jmath}\right.$ & $T_{\min }$ & $M_{\text {min }}$ & & $\gamma_{\min }$ \\
\hline$I=1$ & 30.40 & 29.653389 & 37.37 & 1054.9 & & - \\
\hline & 3919 & & 3432 & 65987 & & \\
\hline$I=10$ & 109.3 & 107.930277 & 36.72 & 895.47 & & 0.49 \\
\hline & 88207 & & 1069 & 6722 & 7302 & \\
\hline$I=10$ & 122.6 & 121.601956 & 37.22 & 956.76 & & 0.50 \\
\hline & 97944 & & 1689 & 9137 & 3436 & \\
\hline$I=100$ & $00 \quad 163.4$ & 162.176815 & 32.86 & 997.68 & & 0.43 \\
\hline & 89763 & & 0396 & 096 & 6385 & \\
\hline
\end{tabular}


a)
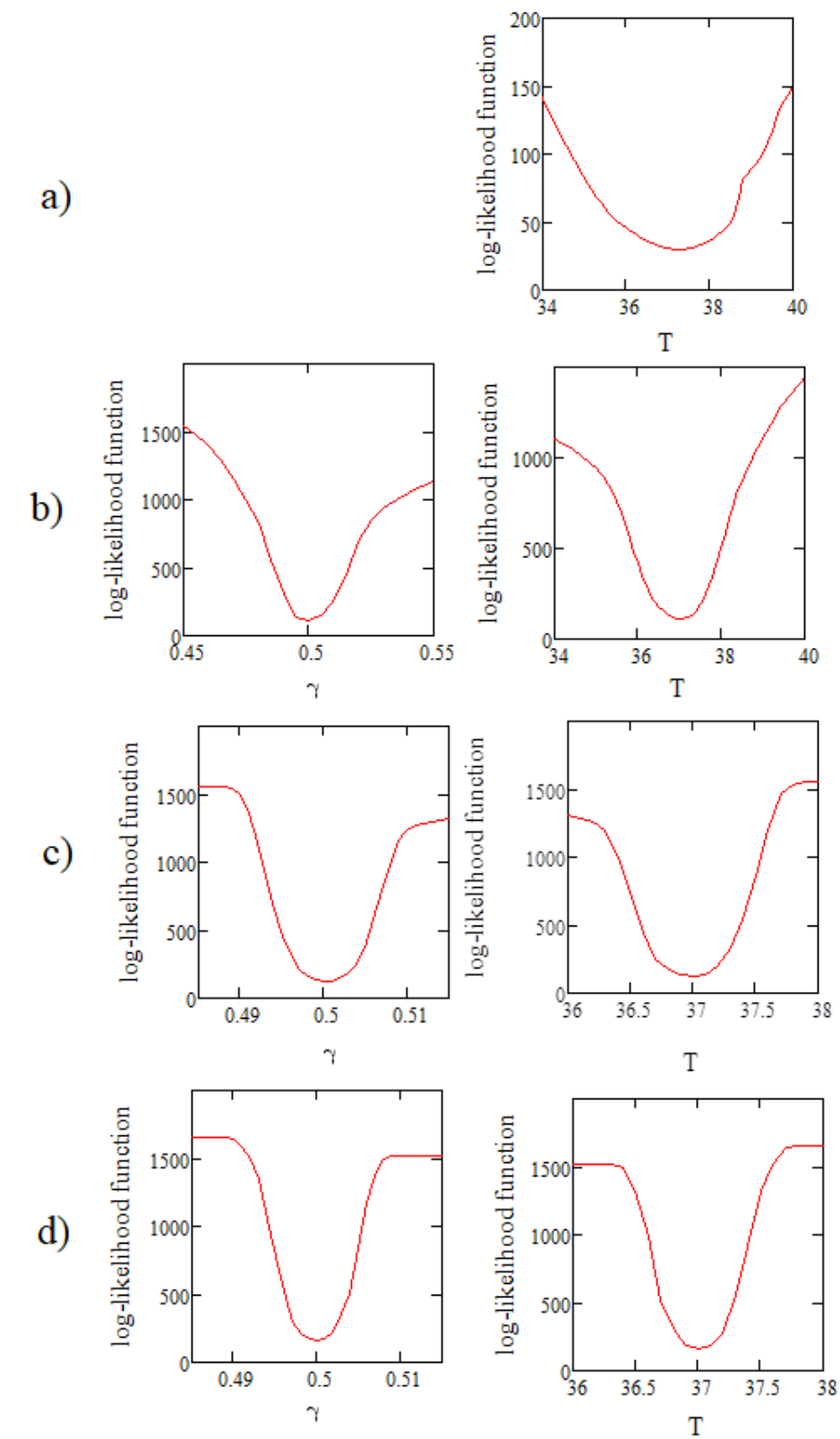

Fig. 1. Dependence of log-likelihood function on parameters, when:

a) $I=1$; b) $I=10$; c) $I=100$; d) $I=1000$.

The dependence of log-likelihood function of parameters $\gamma$ and $T$ in the optimal point is depicted in Fig.1. Hence the SAA enable us efficiently to estimate the parameters of LITD by likelihood method.

\section{Likelihood ratio test for fitting distribution.}

The likelihood ratio method can be applied to fitting to data the multivariate model with maximum likelihood estimation, obtained according to approach described in the previous sections (Casella and Berger, 2002). 
The pulse intensity fluctuation is determined with a laser every degree from $F=25$ to $F=50$. Note that standard deviation of pulse intensity fluctuation is increasing as averaged applied fluence intensity increased (4). Let the error is distributed according to Gauss's law.

Considering the likelihood ratio test for distribution fitting to some data sample, assume some set of parameters of the model to be given, namely, in our case $T, M, \gamma$. Further 1000 multivariate normally distributed random vectors with the obtained parameter estimates are generated and a likelihood ratio test is performed in the following way.

Namely, the empirical distribution function of the values of log-likelihood function is calculated for generated vectors, fitted with the likelihood value computed for the initial data sample (Casella and Berger, 2002). The hypothesis about the data distributed according to the law of Gauss was accepted with significance $14.5 \%$.

Then the law of Cauchy was generated, and verified that is distributed by the law of Gauss. In this case, the hypothesis was rejected with $5 \%$ probability of error.

\section{Conclusions}

The statistical modeling to a series of multiply pulse laser damage according to the normal distribution were developed. Monte Carlo method has been used to compute multiple integrals of LITD testing. Data were estimated via a statistic approach involving surface, densities, threshold, number of pulses, deformation evaluation. Taylor's law was used for modeling the standard deviation, because of increasing fluence intensity. Random sample of fluencies of pulses by computer simulation was generated and its optimal values by likelihood method were obtained. The damage occurred within a small fluence range. The likelihood ratio method for fitting distribution to Gauss was approved.

\section{References}

Batavičiute, G., Grigas, P., Smalakys, L. and Melninkaitis, A. (2013). Revision of laserinduced damage threshold evaluation from damage probability data, Review of Scientific Instruments, 84.

Porteus, J. O., Seitel, S. C. (1984). Absolute onset of optical surface damage using distributed defect ensembles, Appl. Opt. 23, 3796-3805.

Bernhardt, A., Starke, A. (1994). ISO 11254: an international standard for the determination of the laser-induced damage threshold, Laser-Induced Damage in Optical Materials, 2114, 703-7013.

Taylor, L. R. (1961). Aggregation, variance and the mean, Nature. 189, 732-735.

Shapiro, A., Dentcheva, D., Ruszczynski, A. (2009). Lectures on stochastic programming: modeling and theory, Society for Industrial and Applied Mathematics Philadelphia, PA, USA.

Sakalauskas, L. (2002). Nonlinear stochastic programming by Monte-Carlo estimators, European Journal on Operational Research, 137, 558-573.

Casella, G., Berger, R. L. (2002). Statistical inference, 2nd ed. Duxbury Press.

Ingrida Vaičiulyte, Assoc. Prof. Dr., is a dean of Business and Technologies Faculty of Šiauliai State College. 
Leonidas Sakalauskas, Prof. Habil. Dr., is a principal researcher at Vilnius University Institute of Data Science and Digital Technologies. He is an associate professor at Vilnius Gediminas Technical University.

Ingrida Vaičiulytė, Assoc. Prof. Dr., is a dean of Business and Technologies Faculty of Šiauliai State College.

\title{
LAZERIO PAŽAIDOS SLENKSČIO STATISTINIS MODELIAVIMAS
}

\author{
Leonidas Sakalauskas, Ingrida Vaičiulytė
}

\section{Santrauka}

Monte Karlo eksperimentai yra efektyvus įrankis Lazerio Indukuotos Pažaidos Slenksčio (LIDT) tyrimui su impulsiniais lazeriais. Šiame darbe nagrinejjamas nuoseklios paieškos Monte Karlo seriju ivverčiais metodas LITD testavimui su lazerio impulsų pluoštu ir palyginimas su Imties vidurkio aproksimacijos (SAA) metodu. Hipotezei apie duomenu atitikimą skirstiniui priimti arba atmesti naudojamas tikètinumo santykio testas.

Raktiniai žodžiai: Lazerio indukuotos pažaidos slenkstis, Monte Karlo metodas, Imties vidurkio aproksimacija, Didžiausio tiketinumo metodas. 